\title{
The Effect of Homogenizing on the Quench Sensitivity of 6082
}

\author{
P.A. Rometsch ${ }^{1}$, S.C. Wang, A. Harriss, P.J. Gregson, M.J. Starink \\ Materials Research Group, School of Engineering Sciences, University of Southampton, Highfield, \\ Southampton, SO17 1BJ \\ ${ }^{1}$ currently at Hydro Aluminium, Extrusion Technology Centre, N-0240 Oslo, Norway
}

Keywords: 6xxx alloys, quench factor, ageing, modelling, homogenizing.

\begin{abstract}
Hardness data for cast, homogenised, solutionised and subsequently peak aged 6082 samples that had undergone a range of homogenizing and quenching treatments can be modelled well using a recently derived model. Hardness increases with homogenizing temperature and time for all quenched conditions. In contrast with extruded 6082 alloys, the homogenizing condition has little effect on quench sensitivity, even though the density of dispersoids, which act as nucleation sites for non-hardening precipitates, decreases markedly on increasing homogenizing temperature.
\end{abstract}

\section{Introduction}

Homogenizing is performed in order to dissolve the cast eutectic structures and precipitate dispersoids, which control grain size during hot working. A high homogenizing temperature is beneficial in terms of breaking up the eutectic structures but is considered detrimental to dispersoid distribution as it causes a lower density of dispersoids, which is less effective in controlling the grain structure. Whilst this high density of dispersoids is beneficial for controlling the grain structure it may be detrimental to the quench sensitivity of the hot worked alloy, i.e. for extruded 6082 a reduction in the age hardening that can be achieved after quenches at medium cooling has been linked to a high density of dispersoids [1]. This effect is especially important for thick section extrusions.

To further clarify the mechanisms determining quench sensitivity, the quench sensitivity of a cast and homogenised 6082 alloy (i.e. not extruded) which had received a range of homogenizing treatments and quenching treatments was studied by hardness tests on peak aged samples. The hardness data are modelled using a recently derived model for hardness evolution in quenched and aged samples [2], which is based in part on classical quench factor analysis [3,4].

\section{Experimental}

A single batch of $\mathrm{Al}$ alloy 6082, with composition $\mathrm{Al}-1.01 \mathrm{Si}-0.68 \mathrm{Mg}-0.44 \mathrm{Mn}-0.19 \mathrm{Fe}-0.03 \mathrm{Cu}-$ $0.02 \mathrm{Zn}-0.01 \mathrm{Ti}$ (wt\%) was studied. As-cast billets were homogenized by heating at 40 or $150^{\circ} \mathrm{C} / \mathrm{h}$ (average heating rate for $\mathrm{T}>300^{\circ} \mathrm{C}$ ), held for 2 or 8 hours at 520 to $585^{\circ} \mathrm{C}$ and subsequently quenched. Hardness samples were machined from the homogenized billets. Subsequently, the samples were solution treated for $10 \mathrm{~min}$ at $530^{\circ} \mathrm{C}$ and cooled/quenched using different continuous cooling and interrupted quench procedures, including a quench in water at $20^{\circ} \mathrm{C}$ (RTWQ) or at $100^{\circ} \mathrm{C}$ (BWQ), forced air cool (FAC), slow air cool (SAC) and furnace cool (FC); the step quenches included holds at $400,350,300$, and $250^{\circ} \mathrm{C}$ for $3 \mathrm{~min}$ and at $350^{\circ} \mathrm{C}$ for $1 \mathrm{~min}$. For all quenching/cooling treatments the temperature of the sample was recorded using a thermocouple attached to the sample (see Ref [2]). All samples were subsequently naturally aged for 1 week and then aged for $8 \mathrm{~h}$ at $175^{\circ} \mathrm{C}$ in order to obtain peak strength.

The dispersoid distributions are studied by transmission electron microscopy (TEM). For TEM, selected specimens were ground and electropolished in $20 \%$ nitric acid in methanol at $-20^{\circ} \mathrm{C}$. The foils were examined in a JEOL 2000FX TEM operated at $200 \mathrm{kV}$. 


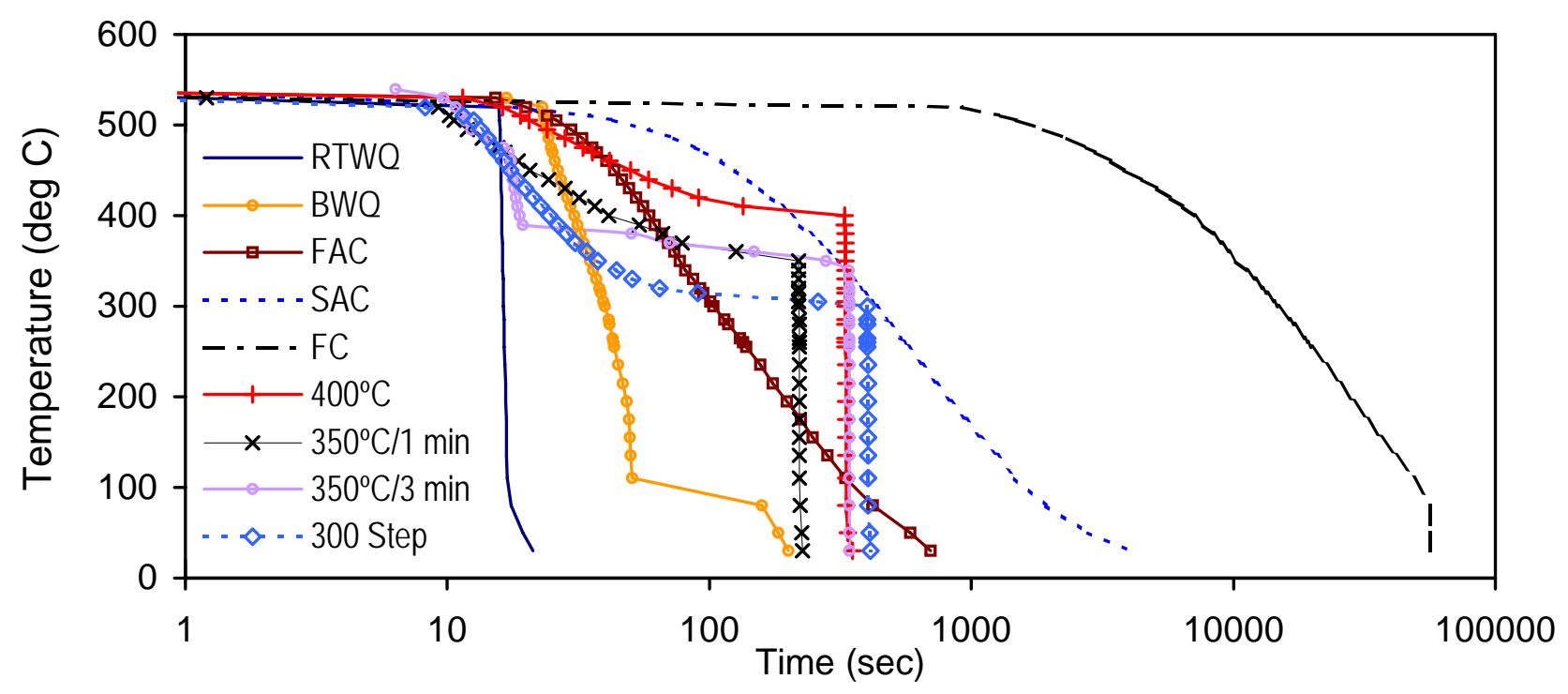

Fig. 1: Temperature during continuous cooling and interrupted quenches.

\section{Model for quench sensitivity}

In this contribution a brief description of the quench factor model is provided. A full description of the model is given elsewhere [2] and possible improvements in quench factor analysis (QFA) are discussed in Ref. [5]. The present model is in several aspects similar to the model in Refs. [1,4].

In the present model quench sensitivity is assumed to arise as a result of precipitation during the quench, which results in a reduced capability of hardening during subsequent ageing. The precipitating species responsible for quench sensitivity in 6xxx alloys is generally assumed to be nonhardening $\mathrm{Mg}_{2} \mathrm{Si}$ precipitates. In our model we assume one single hardening phase ( $\beta$ ", see $[1,6,7,8])$ and one single non-hardening phase, and we calculate the concentration of dissolved elements, $\mathrm{C}_{\mathrm{SS}}$, at the various stages during the sequence of heat treatments (Fig. 2). Assuming further that the solvus can be described by a regular solution model we can approximate:

$$
\left[C_{M g}\right]^{3}=1.73 \exp \left(\frac{\Delta S^{o}}{R}-\frac{\Delta H^{o}-2 \Omega}{R T}\right)
$$

where $\Delta H^{\circ}$ is the standard enthalpy of reaction, $\Omega$ is the contribution of particle curvature to the enthalpy of reaction, $\Delta S^{\circ}$ is the standard entropy of reaction, $\left[C_{M g}\right]$ is the concentration of $\mathrm{Mg}$ in solid solution, $\left[C_{S i}\right]$ is the concentration of $\mathrm{Si}$ in solid solution and 1.73 is the stoichiometric ratio of atomic weights.

Fig. 2: Schematic Al- $\mathrm{Mg}_{2} \mathrm{Si}$ quasibinary phase diagram, showing the effect of heat treatment on the effective $\mathrm{Mg}_{2} \mathrm{Si}$ concentration in solid solution. The alloy limit is designated $\mathrm{C}_{\mathrm{SS} \text { (MAX) }}$.

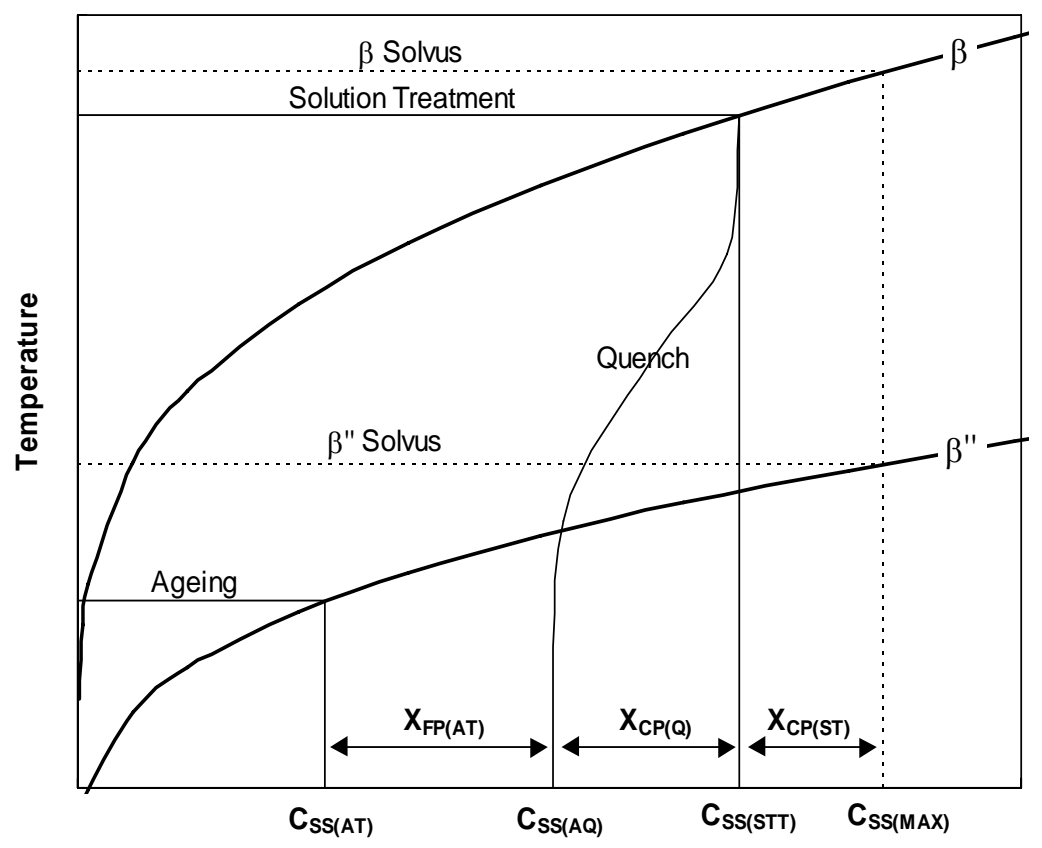


It then follows that the effective concentration of $\mathrm{Mg}_{2} \mathrm{Si}$ in solid solution that is available for forming either hardening or non-hardening precipitates is given by:

$$
C_{S S}=\left[C_{M g}\right]+\frac{\left\lfloor C_{M g}\right\rfloor}{1.73}
$$

From Fig. 2 it follows that the amount of $\mathrm{Mg}_{2} \mathrm{Si}$ lost to coarse non-hardening precipitates during solution treatment below the solvus and during quenching are given by:

$$
\begin{aligned}
& X_{C P(S T)}=C_{S S(M A X)}-C_{S S(S T T)} \\
& X_{C P(Q)}=C_{S S(S T T)}-C_{S S(A Q)}
\end{aligned}
$$

and the amount of $\mathrm{Mg}_{2} \mathrm{Si}$ that is available to form fine hardening precipitates at the ageing temperature is:

$$
X_{F P(A T)}=C_{S S(A Q)}-C_{S S(A T)}
$$

Based on the pioneering work of Evancho and Staley [13], logged quench curves (Fig. 1) and corresponding hardness values were used to construct the QFA under the assumption that the transformation reaction is additive. C-curves were modelled using the equation

$$
C_{t}=-k_{1} k_{2} \exp \frac{k_{3} k_{4}^{2}}{R T\left(k_{4}-T\right)^{2}} \exp \frac{k_{5}}{R T}
$$

where $C_{t}$ is the critical time required to precipitate a constant amount of non-hardening precipitates, $k_{1}$ to $k_{5}$ are fittable parameters: $k_{1}$ is the $\ln$ of the fraction untransformed, $k_{2}$ is related to the reciprocal of the number of nucleation sites, $k_{3}$ is related to the nucleation energy, $k_{4}$ is related to the solvus temperature, $k_{5}$ is related to the activation energy for diffusion, and $T$ is the temperature. For a given C-curve modelled using Eq. 7, quench factors, $Q$, were determined for each experimental quench curve in Fig. 1 using the integral

$$
Q=\int_{t_{0}}^{t_{f}} \frac{d t}{C_{t}(T)}
$$

where $t$ is the time, $t_{o}$ is the time at the start of the quench and $t_{f}$ is the time at the end of the quench.

To describe the kinetics of the precipitation reaction during the quench the Starink-Zahra equation $[9,10]$ was adapted for QFA using concentrations instead of hardness values:

$$
\frac{C_{S S(A Q)}}{C_{S S(S S T)}}=\left[\frac{(-K Q)^{n}}{\eta_{i}}+1\right]^{-\eta_{i}}
$$

where $K$ is a temperature-dependent constant, $n$ is the reaction exponent for coarse non-hardening precipitates and $\eta_{i}$ is the (adjustable) impingement factor for coarse non-hardening precipitates. Previous work $[2,5,9,10,11]$ has indicated that $n$ should equal $1 \frac{1}{2}$ or $2 \frac{1}{2}$, whilst $\eta_{i}$ equals about 1 . The adoption of Eq. 8 results in transformation curves that are different from those predicted by classical QFA which adopts the Johnson-Mehl-Avrami equation. This difference can be especially substantial in the later stages of the transformation, when impingement of diffusion fields becomes important.

To enable ageing kinetics to be modelled at different ageing temperatures, the temperaturecorrected time [1] was introduced to describe the breakdown of the supersaturated solid solution during ageing. These aspects of the model [2] will not be used in the present paper, as all samples are assumed to have reached peak strength.

The total predicted hardness is the sum of the intrinsic hardness $\left(H V_{i}\right)$, the solid solution hardening contribution $\left(\Delta H V_{s s}\right)$ and the precipitation hardening contribution $\left(\Delta H V_{p p t}\right)$ :

$$
H V_{t}=H V_{i}+\Delta H V_{s s}+\Delta H V_{p p t}
$$

In general the solid solution hardening contribution can be approximated well by:

$$
\Delta H V_{s s}=A_{1}\left(C_{s S(A T)}\right)^{2 / 3}
$$


where $A_{1}$ is a solid solution hardening constant and $C_{S S(A T)}$ is the concentration of $\mathrm{Mg}_{2} \mathrm{Si}$ in solid solution at the ageing temperature. For the present peak aged samples we can take:

$$
\Delta H V_{p p t}=A_{2} X_{F P(A T)}^{1 / 2}
$$

where $A_{2}$ is a constant, and $X_{F P(A T)}$ is the amount of $\mathrm{Mg}_{2} \mathrm{Si}$ bound up in the hardening $\beta$ " precipitates, i.e. $X_{F P(A T)}=C_{S S(A Q)}-C_{S S(A T)}$.

\section{Results and Discussion}

TEM micrographs of the 6082 samples homogenized for $2 \mathrm{~h}$ at 520 and $585^{\circ} \mathrm{C}$ (Fig. 3) reveal that the density of the Mn containing dispersoids decreases with increasing homogenization temperature. Additional TEM work [12] revealed the presence of fine $\beta^{\prime \prime}$ precipitates as well as coarse $\beta^{\prime}$ precipitates which had nucleated on the dispersoids.

The hardness data obtained for the homogenizes and quenched 6082-T6 samples (Fig. 4) shows consistent trends and the standard deviation in the hardness data per sample is low (average 0.9). Fig. 4 shows that hardness increases with increasing homogenization time and temperature, for all quenches except for the very slow FC treatment for which hardness for all samples has decreased to about $40 \mathrm{HV}$. This is thought to be due to increased dissolution of as-cast eutectic structures during homogenizing which increases the amount of solute available for precipitation hardening, provided quenching is sufficiently fast to retain at least some solute in solution.

Quench sensitivity can be defined in various ways. It has been defined as the absolute loss in property (e.g. strength or hardness) with reducing quenching rate or log of quench rate [13] (the absolute property loss definition), or as the relative loss in properties by normalising with the maximum loss in properties that occurs for extremely slow quenches. One may further either assume that for each alloy properties after RTWQ (and subsequent ageing) are independent of pre-quenching treatment (e.g. independent of homogenizing conditions) or one may consider that they depend on pre-quenching treatment. For the present data no significant difference in quench sensitivity can be detected if the dependency of RTWQ+age hardness on homogenizing conditions (Fig. 4) is taken into account, and this holds both for the absolute and relative property loss cases. Only if RTWQ+T6 hardness is assumed to be insensitive to homogenizing conditions, quench sensitivity appears to increase slightly with reducing homogenizing temperature.

In the modelling of the data, model parameters are determined in three ways. Firstly, for parameters for which reliable literature data is available a fixed value can be adopted. Secondly, for parameters that do not depend on homogenizing treatment a single value can be fitted by minimizing the root mean square error (RMSE) of model predictions. Thirdly, for parameters that depend on homogenizing treatment 5 values can be determined, one for each homogenizing treatment, by minimizing the RMSE. It was found that the model could predict unseen data (i.e. test data) to an accuracy of about $7 \mathrm{HV}$ (RMSE). It was observed that a range of slightly different parameter sets which all led to a similar RMSE could be obtained, and the selection depended on whether parameters were assumed to have single values or different values for each homogenizing treatment. This combination of good model accuracy, with some ambiguity about the most appropriate values for the parameters is in line with earlier assessment of the model using other datasets [2,5], and means that caution needs to be exercised in interpreting the assessed model parameters. In line with the discussion on the different possible definitions of quench sensitivity several modelling attempts were tried. Following the assumption that RTWQ+age hardness depends on homogenizing treatment, first a modelling approach in which the maximum hardness was allowed to vary between the different homogenizing treatments was adopted. In this approach no significant variation of $k_{2}$ was detected and hence the quench sensitivity became independent of homogenizing condition. Following the alternative assumption that RTWQ+age hardness does not depend on homogenizing treatment, a second modelling approach in which a single value of the maximum hardness was 

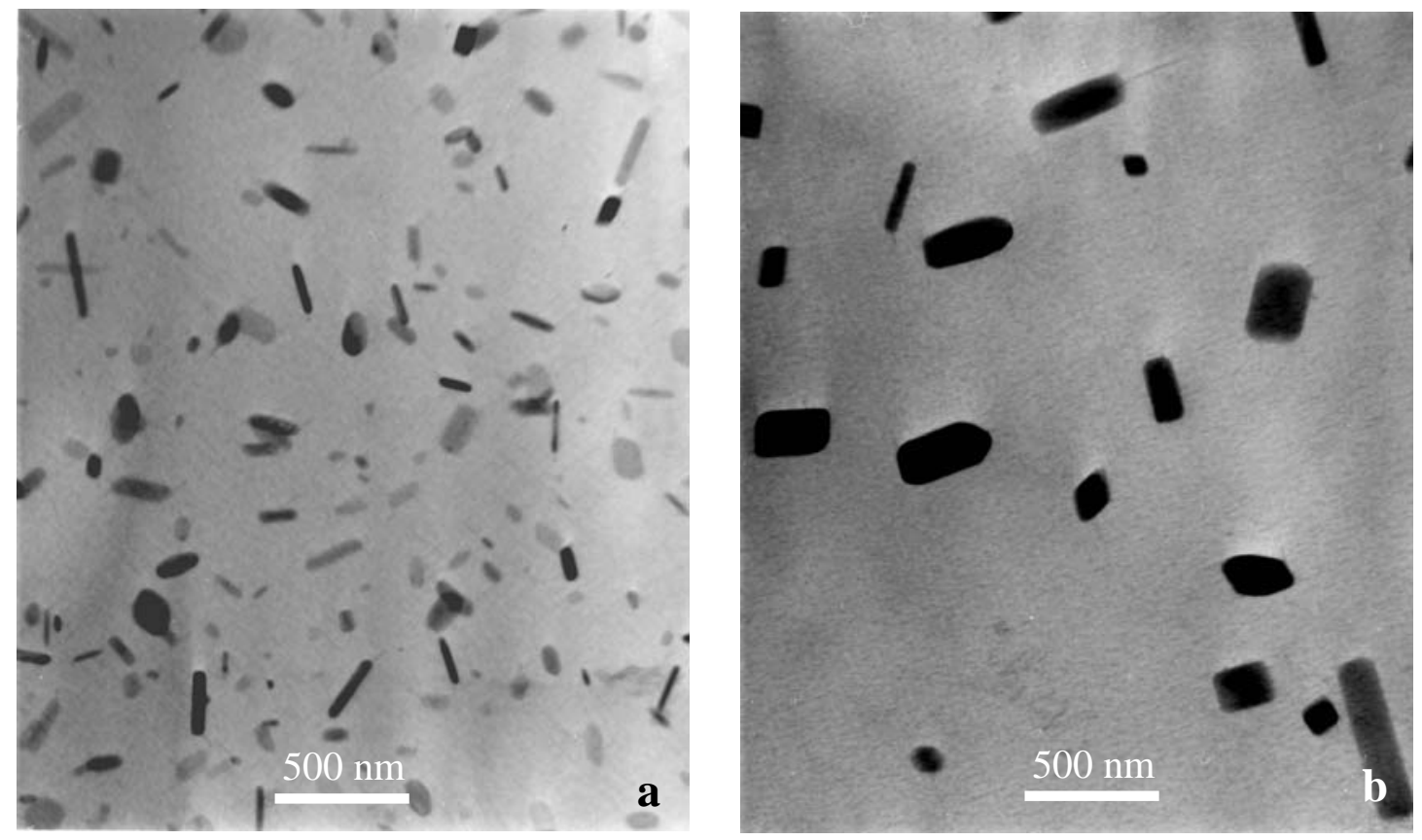

Fig. 3: TEM micrographs (Bright Field) showing Mn containing dispersoids in 6082-T6 samples homogenized for $2 \mathrm{~h}$ at 520 (a) and $2 \mathrm{~h}$ at $585^{\circ} \mathrm{C} \mathrm{(b).}$

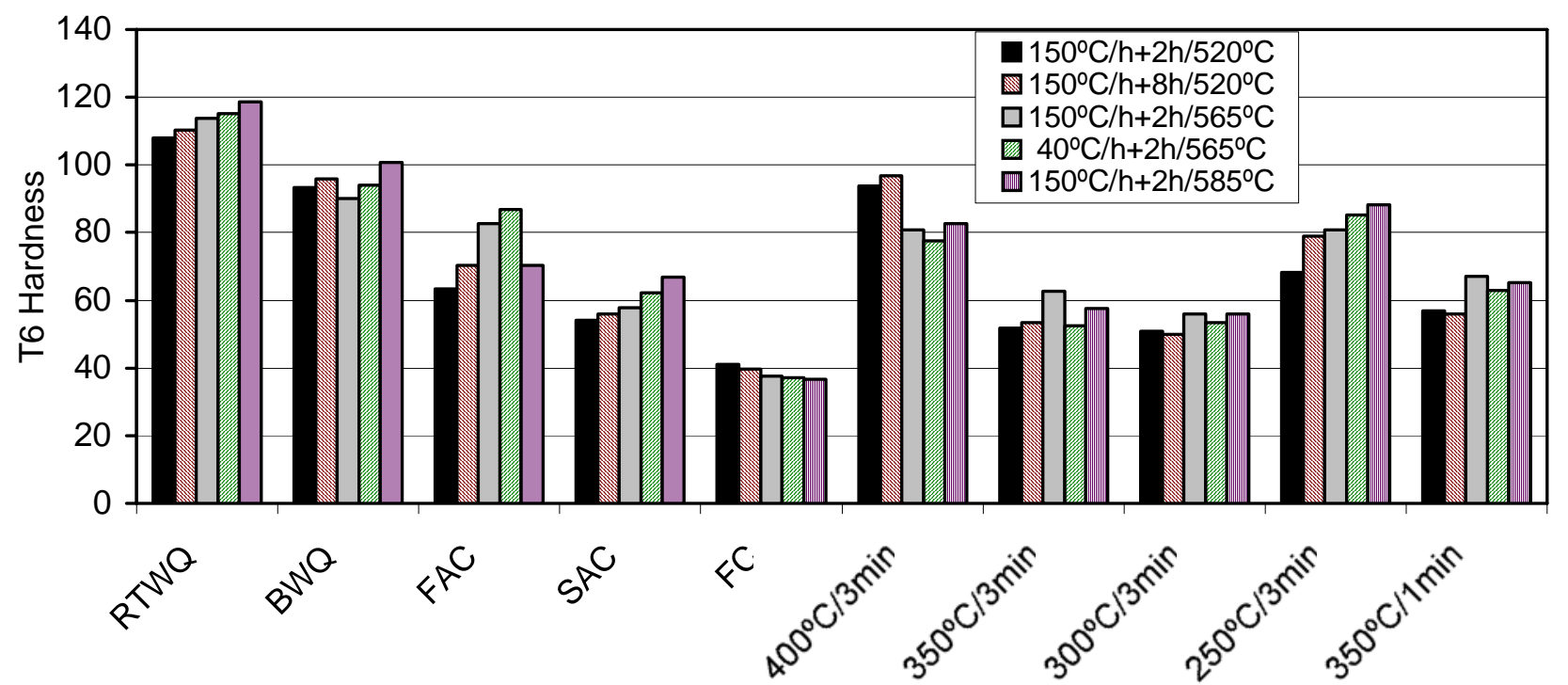

Fig. 4: Hardness data for the 6082-T6 homogenized and quenched using the procedures indicated.

attempted. In this approach a limited increase in $k_{2}$ (maximum increase of a factor 2) with decreasing homogenizing temperature is detected which appears to be inconsistent with the observed decrease in the number of nucleation sites for formation of non-hardening particles with increasing homogenizing temperature (a factor 8, estimated from Fig. 3). At present it is believed that the increase in hardness with homogenizing treatment is a real effect and hence it is thought that the quench sensitivity of the present cast and homogenized material does not significantly vary with homogenizing conditions, but more experiments would be needed to confirm this. These observations suggest that for relatively fast quenches, even though precipitation of non-hardening precipitates on dispersoids undoubtedly occurs, the density of dispersoids is not the dominant factor determining quench sensitivity. The quench sensitivity of our cast and homogenized 6082 samples is comparable to that of extruded and homogenized 6082 alloy homogenized $4 \mathrm{~h} / 530^{\circ} \mathrm{C}$, whilst extruded 6082 homogenized $3 \mathrm{~h} / 580^{\circ} \mathrm{C}$ is significantly less quench sensitive [1]. Thus, the effect of 
homogenizing appears to be different for extruded and non-extruded 6082 . This may be due to the stored deformation energy of hot worked alloys which influences recrystallisation and grain growth during homogenizing. Differences in grain size may subsequently influence quench sensitivity through influencing vacancy annihilation during quenching, which in turn influences diffusion rates. Thus, in this interpretation dispersoid size in extruded alloys is correlated with quench sensitivity, even though dispersoids have a limited direct influence on events during the quench which determine quench sensitivity. Support for this interpretation can be obtained from the value of $k_{5}$ obtained from the model fitting, which at $52 \mathrm{~kJ} / \mathrm{mol}$, is reasonably close to the activation energy for vacancy diffusion. Further experiments are needed to confirm the interpretations based on the present data, and, even though the model can fit the measured data well, the identification of the different parameters within it may require reinterpretation.

\section{Conclusions}

The density of Mn containing dispersoids in cast and homogenised 6082, which are nucleation sites for non-hardening precipitates, decreases markedly with increasing homogenizing temperature. Hardness data on homogenized, solution treated and aged samples which were quenched using a wide range of cooling rates show hardness increases with increasing homogenizing temperature. However, quench sensitivity varies little with homogenizing temperature. A recently derived model for quench sensitivity fits well to the present hardness data, and a detailed assessment using the model suggests that precipitation of non-hardening precipitates on dispersoids is not the main factor determining quench sensitivity.

\section{Acknowledgements}

Financial support of The Luxfer Group and technical discussions with Mr. M. Jarrett are gratefully acknowledged. Alloys were provided by British Aluminium Extrusions (currently Alcoa Europe).

\section{References}

1 D.H. Bratland, Ø. Grong, H. Shercliff, O.H. Myhr and S. Tjøtta, Acta Mater. Vol 45, 1997, 1-22

2 P.A. Rometsch, M.J. Starink and P.J. Gregson, in 'Advances in the Metallurgy of Al Alloys', Proc. from the Mater. Solutions Conf. 2001, J.T. Staley Honorary Symp., Nov. 5-8, 2001, Indianapolis, M. Tiryakioglu, ed. (ASM International, Materials Park, Ohio, 2001) pp. 195-203

3 J. W. Evancho and J.T. Staley, Metall Trans. Vol. 5 (1974) 43-47

4 J. T. Staley, Mater. Sci. Technol. Vol. 3 (1987) 923-35

5 P.A. Rometsch, M.J. Starink and P.J. Gregson, Mater. Sci Eng. A Vol. 339 (2003) 255-64

6 G.A. Edwards, K. Stiller, G.L. Dunlop and M.J. Couper, Acta Mater. Vol. 46 (1998) 3893-3904

7 M.J. Starink, Mater. Sci. Eng. A, vol. A276 (1999) 289-92

8 C.D. Marioara, S.J. Andersen, J. Jansen and H.W. Zandbergen, Acta Mater. Vol 49 (2001) 321-8

9 M.J. Starink and A.-M. Zahra, Thermochim. Acta Vol. 292 (1997) 159-68

10 M.J. Starink and A.-M. Zahra, Phil. Mag. A Vol. 77 (1998) 187-99

11 M.J. Starink and A.-M. Zahra, Acta Mater. Vol. 46 (1998) 3381-97

12 S.C. Wang, P.A. Rometsch and M.J. Starink, unpubl. work, University of Southampton (2001)

13 D.L. Zhang and L. Zheng, Metall. Mater. Trans. A Vol. 27 (1996) 3983-91 